\title{
Gender may not be the biggest factor in women doctors' lower patient mortality rates
}

\author{
— Cite as: CMAJ 2021 August 23;193:E1308-9. doi: 10.1503/cmaj.1095957
}

Posted on cmajnews.com on August 6, 2021

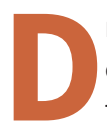
r. Andrea Lavoie, an interventional cardiologist in Regina, has a reputation for not rushing clinical interactions. "I often get comments like, 'You take a really long time with your patients, doc,' from some of the staff I work with," she said.

Although spending extra time with patients could play a part in women physicians' lower patient mortality rates, physician gender may not matter as much as previously thought, according to a new study of Canadian physicians and patients, published in JAMA.

Researchers compared in-hospital deaths among more than 170000 patients admitted to general medical wards in seven Canadian hospitals between 2010 and 2017, who were cared for by 54 female and 118 male internists. The study uses male and female (sex) and men and women (gender) interchangeably, without distinguishing between them.

The mortality rate among patients cared for by female physicians was $0.47 \%$ lower than that for male physicians, tracking closely the results of a large American study published in 2017 that showed a $0.43 \%$ lower 30 -day mortality for the patients of female doctors.

This gap held when the Canadian researchers adjusted for patient characteristics such as age, gender and disease acuity, and for hospital differences. But when they accounted for physician experience, the difference between male and female doctors' patient mortality rates wasn't statistically significant, except marginally so in cases where the "most responsible physician" was also the attending and discharging doctor.

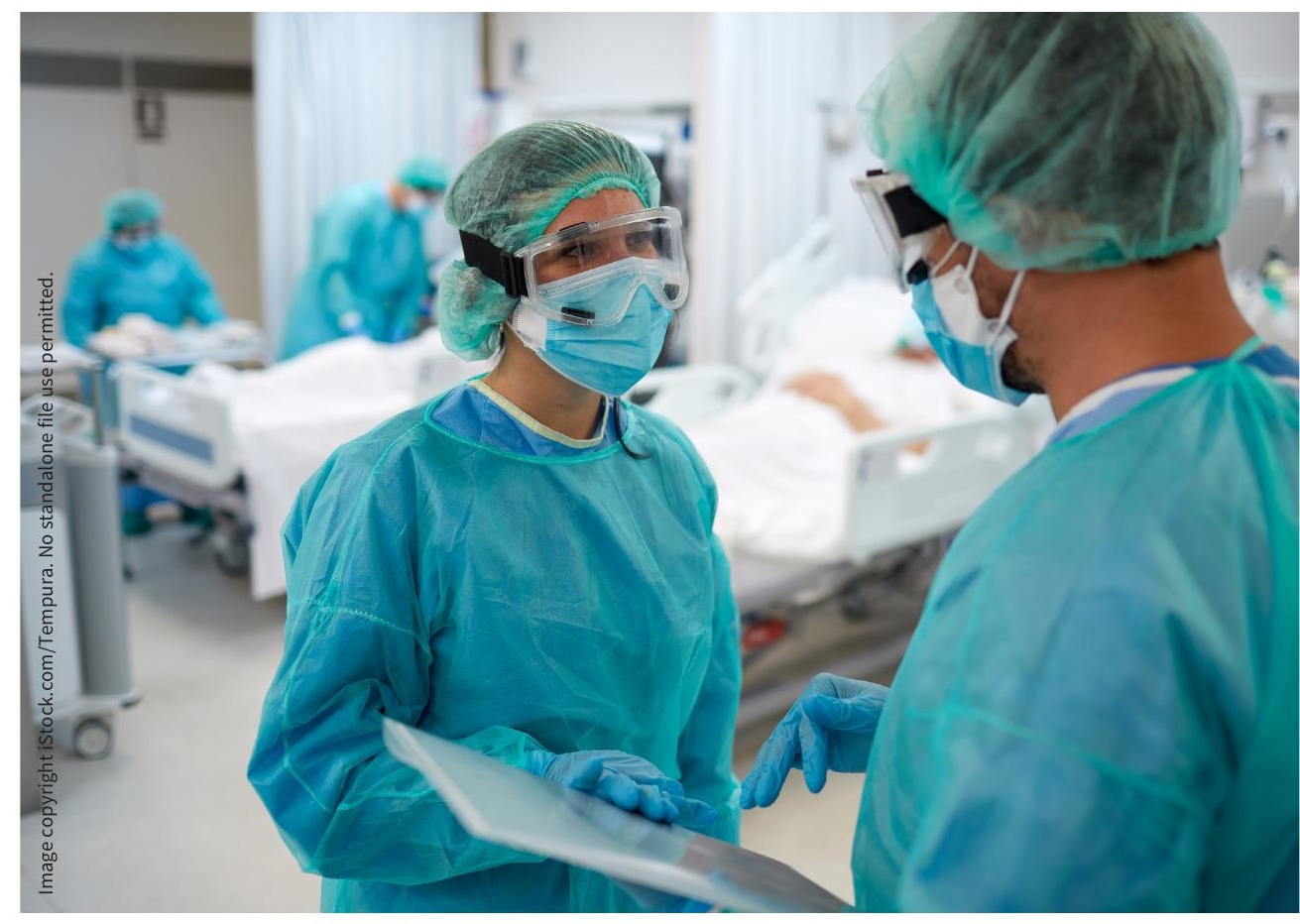

Patients are less likely to die under the care of women doctors, but this difference may have more to do with experience than gender.

Male physicians in the study had more years of experience on average than their female peers, explained lead author Anjali Sergeant, a third-year medical student at McMaster University in Hamilton. As such, "the mortality difference between male and female physicians we report could be partially because more female docs are younger."

In Canada, most physicians under 40 are women, but most older doctors are men, Sergeant said. "Newer, younger doctors may be more up to date on clinical guidelines, which some studies have shown leads to better patient outcomes."

The researchers also compared differences in processes of care, such as prescrib- ing medications and ordering diagnostic imaging and bloodwork. They found that women physicians requested more diagnostic tests than men, but that didn't have any bearing on patient mortality.

"I don't think this study should be interpreted as viewing male and female doctors as very different from each other," Sergeant said. "We know that a lot of the way we behave is mediated by what we're taught."

However, Sergeant noted that the study's findings put the lie to sexist assumptions about women's competence as doctors. "Female physicians should be respected... because we can see that they're performing just as well as, if not better than their male counterparts." 
The researchers acknowledged there may be other factors at play beyond the variables they could collect from electronic medical records. Other studies have found that female doctors are more likely to practise patient-centred care, take more time talking with their patients, and display more empathy.

"Looking at these sorts of variables and how they impact mortality rates would be really interesting," although they're more difficult to study, Sergeant said.

Dr. Moira Kapral, director of general internal medicine at the University of Toronto, practises at one of the hospitals included in the study. She was relieved the results showed little difference between male and female physicians.
"I'm old enough to have started [practising medicine] at a time when there were hardly any women in our particular field," Kapral explained. Since then, "women have often faced obstacles in medicine, and sometimes patients don't want to be seen by women."

For Kapral, the key takeaway from Sergeant and colleagues' study is that patients can be confident that a physician's gender doesn't have much impact on the quality of care. "That shouldn't be a factor in deciding who your physician should be or worrying about what your outcomes are likely to be."

Lavoie said the study has prompted interesting discussions with her peers in
Regina that she plans to carry forward to their local journal club. "So [if we can rule out physician gender as a factor in patient mortality], what are the best ways for us to deliver care to patients so that we improve their outcomes. That's really the bottom line, right?"

\section{Greg Basky, Saskatoon, Sask.}

Content licence: This is an Open Access article distributed in accordance with the terms of the Creative Commons Attribution (CC BY-NC-ND 4.0) licence, which permits use, distribution and reproduction in any medium, provided that the original publication is properly cited, the use is noncommercial (i.e., research or educational use), and no modifications or adaptations are made. See: https://creativecommons.org/ licenses/by-nc-nd/4.0/ 